\title{
Study on Professional Development Training Method of Open and International University English Teachers
}

\author{
Li Cao ${ }^{1, a}$ \\ ${ }^{1}$ Jilin Radio and TV University, Changchun, Jilin, Dalian, 130022 \\ ${ }^{a}$ email
}

Keywords: English Teachers, Professional Development; International Training, Open University

\begin{abstract}
The wave of globalization accelerated process of Chinese English education reform. Teacher as an important factors that can support the development of education, play an important role in the training of personnel. Faced with the impact brought about by globalization, promoting teachers' professional development and developing international training is a fundamental measure to cope with the education reform.
\end{abstract}

\section{Introduction}

With the mutual integration of national economies and the development of economic globalization promote the exchanges and cooperation in education and culture of each country. National education reform and teacher professional development has become an important issue in the world of educational development, the interaction between the two mutual restraint. "Long-term Development and Education Plan (2010-2020)" clearly states that colleges and universities should actively carry out multi-level, wide-ranging international exchanges and cooperation, enhance the level of internationalization of teachers' professional development. This means that China's education has entered a new development, as the main body of University personnel training, played a vital role in the development of education reform, teacher education as a performer, the international development of education is to achieve the prerequisite of English teachers' professional development international so as to promote cultural exchange and integration. Therefore, international training Open University English teacher professional development is of great significance.

\section{The Development Status of the Open University English Teachers and Problems}

Today, the community of the importance of education continues to improve, increasing funding, increased Open University English teacher professional development opportunities, the overall quality of English teachers and English teaching quality is greatly improved. However, the increase in the quality of teaching English at the same time, colleges and universities to discover English Teacher Professional Development Problems, always remain sober-minded, so as to promote the Open University English teachers' professional development [1].

Actively participate in various education and scientific research activities are open to college English teachers' professional development of the fundamental requirements and objectives, it is not only an important way to enhance the quality of English teachers, but also teachers of self-examination, the main method to enhance their own level of education. But in a long time, my English teacher will be too much focus on the promotion of students forty-six passing rate in English, and as a teaching quality evaluation and performance assessment of the main basis. College English education, examination-oriented education awareness play a decisive role, to a certain extent, ignored the importance of English teaching and research activities of the teaching and research activities and English Language Teaching Practice separated. Therefore, many English teachers to rely on their own teaching experience conducting educational activities, their own experience in teaching English teaching can not be summarized in theory, difficult to use it to improve their teaching ability. Due to the lack of a clear concept of teaching and research, most of the English teachers in English teaching activities did not develop a clear plan. Teaching and 
research ability to effectively promote English teachers' professional development, research and awareness behind affect the power of English teaching, long-term trend continues, will lead to poor quality of teaching English teachers, restricting the quality of the Open University English Teaching and efficiency, the impact of English education in development and progress.

At present, teaching English teaching activities carried out using a single textbook, English teaching content and means a single, traditional English teaching model can not meet the requirements of modern society. In English teaching, teachers must first tell the English word pronunciation and meaning, and then divide ingredient statement, understand the meaning of the article, the final article in the grammatical phenomenon summarized, this teaching method belongs to exam-oriented education in teaching English dumb , fewer opportunities for students to use English. This way of teaching too much emphasis on the dominant position of teachers, students play the main activity is suppressed, it is difficult to attract students' interest in learning. At the same time, fewer application of multimedia teaching methods, teaching methods and international restructuring, diversification of knowledge and capacity building requirements of the concept of lifelong learning there is a big gap between students' language ability is poor practice, behind international standards development.

\section{The Necessity of Open University English Teachers' Professional Development}

Increasing international exchanges, professional development programs for teachers of English training is imperative, not only to promote the internationalization of training in English education curriculum reform, but also to promote the progress and development of English teachers.

With the accelerating process of globalization, exchanges between different countries and regions of the increasing number of education as an important part of nation-building, and the overall quality of college English teachers have become increasingly demanding. In terms of expertise, not only to master the English teachers of English professional knowledge, but also master the English language background, an international vision, improve their knowledge structure; in terms of cross-cultural communication, familiar with international practices and exchanges related etiquette; in English teaching ability, English language teachers to learn about the latest techniques and teaching methods, update their teaching philosophy, follow the pace of international development; academic exchanges, teaching and research as one of the main tasks of College English teachers should grasp the international language research, development dynamic, and the use of English in the teaching process, at the forefront of English teaching.

English is the world's most used language, university curriculum and teaching activities with international standards development, the only way to cultivate talents with the national level of development. International university courses is not only the requirements of the English curriculum with international feature or set a certain number of international courses, also includes the use of international common language in English Teaching, for example, using original English language learning textbooks. English teacher is perpetrator of international curriculum in English Education is playing an important role, but the key is to achieve the objective of the international programs.

Since China joined WTO, economic development, international education development such internationalization, the internationalization of education and further have a profound impact on the university teachers and students. Develop "GATS" further defined the requirements for the development of higher education. Development of modern education requires a lot of innovative talents, colleges and universities to actively update training model, the government should actively create through international education environment to meet the needs of the community to cultivate innovative talents.

\section{The Factors Affecting the Open University English Teachers Professional Development}

Open University Teachers' Professional Development is the development of the time and to carry out international training activities in favor of English teachers broaden horizons, an international 
development perspective. For the current problems of the Open University English teacher professional development exists, colleges and universities to actively analyze the cause of the problem, so as to formulate appropriate solutions to promote the internationalization of College English Teachers' Professional Development.

Teachers are only through continuous development and learning in order to achieve sustained development of professional competence. Learning English teachers can be analyzed from the following aspects: first, professional knowledge learning time; second, the number and frequency of daily communication; third, professional books cost. Relevant institutions are on the above three aspects of English Teachers investigation. Results from the survey can be found, in addition to teaching, spending five hours a week for reading a number of English teachers English secretary and magazines accounted for $23.9 \%$ of the total number of the survey, the number of teachers spend 3-4 hours reading was 32.2\%, lower $43.9 \%$ in two hours of reading time by the number of the total number of English teachers. In everyday exchanges, the exchange once a week on average $62.8 \%$ of the total number of the number of teachers, number of teachers with zero exchange accounted for $37.2 \%$. In terms of cost of professional books, books each year to purchase $61.1 \%$ of teachers spend less than the number of the total number of 500 yuan [4].

As can be seen from the above three aspects, college English teachers 'professional learning time, the number of academic and professional books less costly, long-term trend continues, it will seriously affect the process of English teachers' professional development. English teacher professional development as the fundamental, only teachers develop independent learning awareness, professional development goal to be achieved.

Professional attitude, as one of the important factors affecting the English teachers' professional development, have a significant impact on the development of English teachers. In the teachers polled believe that $97.9 \%$ of English teachers' professional development important number of the total number, can be seen from this result, the vast majority of English teachers have recognized the importance of professional development.

\section{Promoting International Training Method of English Teachers' Professional Development}

Discussion on the Open University Teachers' Professional Development of international training path, the tide national development, it is possible to stimulate enthusiasm and English teachers' professional development, to improve their English teachers' professional skills and overall quality, improve the Open University English Teaching play an important role on the level.

Teacher training base to play on the professional development of teachers, and guiding role, accelerate and improve teacher training bases, it is possible to provide effective protection for the English teachers' professional development. First, teacher training colleges and universities to increase the base funding, accelerate infrastructure construction, provide a good environment for teacher training. Second, colleges and universities to define their own development positioning, promote research, education, optimization and integration of training institutions, research training to accelerate the integration process, improve the quality of teacher training and benefits. Third, establish a scientific and standardized employment mechanism to attract talented people to join teacher training bases, strengthen the construction of teachers, teacher training base for sustainable development [5]. In addition, to establish a good working relationship between universities and teacher training base and mutual benefit. In the teacher training process, colleges and universities to provide the appropriate practice venues, promoting the combination of theory and practice. Teacher training base capable of delivering high-quality education for college talent and provide theoretical help and guidance, to achieve win-win situation.

School-based training is an important way to enhance the College English Teachers' Quality. Colleges and universities should actively grasp of English Teachers in practical, forward-thinking culture, and promote the smooth development of school-based work. Supervision and management departments to College English Teacher Training to track the establishment of teacher professional development records, to improve the quality and effectiveness of international English teacher training; local conditions, and the time to play the English teacher's initiative to develop 
independent training. Colleges and universities according to their own development, the development of international training programs; analysis of personnel structure university teachers, respecting the wishes of the individual development on the basis of conduct stratified training; English teachers to develop appropriate development goals, to ensure that everyone can participate in the international training, improve the quality of school-based training.

On the basis of colleges and universities to promote local economic development, the establishment of a sound training program, innovative personnel training system, in order to train local talents to meet the needs of socio-economic development. English teachers as implementers of educational activities to raise awareness, awareness of the importance of professional development, actively participate in international training courses, broaden their horizons, rich English basic theoretical knowledge, improve their professional structure, increase the quality and level of English teaching, promote their professional development.

English teachers 'professional development is the inevitable requirement of progress, no teachers' professional development, teacher education mission would be difficult to complete. English teachers' professional development is not only the needs of personal development, but also the needs of universities and social development. International Training Path Open University English teachers 'professional development able to indicate the direction of College English Teachers develop, promote education and international development phase of integration, improve teachers' knowledge of English structure. In promoting international English teacher training colleges and universities to actively change their teaching philosophy, the development of long-term development plan to accelerate teacher training base construction, promote international exchanges and cooperation, strengthen the sense of innovation, improve the level of education of English teachers, and promote the professional development of English teachers .

\section{References}

[1] Chen Yan. College English Teachers' Professional Development and Promotion Measures University [J] Chinese Adult Education, 2014,19: 110-112.

[2] Liu Peihong, Shang Kaikai. Effect of College English Teachers' Professional Development Factors contemporary [J]. educational theory and practice, 2014,12: 150-152.

[3] Yang Yanhua. Local College English Teachers International Construction College Discussion [J] Yulin Normal University, 2015,01: 125-127.

[4] Guo Yan, Xu Jinfen. Construction College English Teachers' Professional Development Community [J]. foreign language, 2015,05: 79-87.

[5] Liu Jianping. English Teachers' Professional Development under the Open University Background [J]. Taiyuan Urban Vocational and Technical College, 2013, 01: 96-97.

[6] Song Hongying. Open Education English Teacher Training International Research [J] Education Research, 2013, 01: 53-57. 